\title{
Avaliação microbiológica de tortas doces comercializadas em feiras especiais da cidade de Goiânia-GO
}

\section{Microbiological evaluation of sweet pies marketed fairs in special city Goiânia-GO}

\author{
Edmar Soares Nicolau ${ }^{1 *}$; Nayana Ribeiro Soares ${ }^{2}$; \\ Julliane Carvalho Barros ${ }^{3}$; Beatriz Severino da Silva ${ }^{3}$; \\ Marco Antônio Pereira da Silva ${ }^{4}$; Sheyla do Ó Cavalcanti ${ }^{5}$
}

\begin{abstract}
Resumo
Tortas doces são alimentos largamente consumidos nas feiras especiais da cidade de Goiânia - GO. Em geral são comercializadas de forma inadequada, sem refrigeração e muitas vezes sem proteção contra os vários tipos de contaminantes, inclusive contaminação microbiana, que pode causar toxiinfecções alimentares aos consumidores. O presente trabalho teve como objetivo avaliar a qualidade microbiológica de tortas doces comercializadas em 105 bancas nas 23 feiras especiais da cidade de Goiânia, e também o impacto da capacitação dos feirantes em Boas Práticas de Fabricação (BPF) na qualidade destes produtos. Os micro-organismos investigados foram aqueles exigidos pelo padrão microbiológico vigente: Salmonella sp, coliformes termotolerantes, Bacillus cereus e Estafilococos coagulase positiva. A temperatura de exposição destes alimentos nas bancas também foi verificada. Um total de 259 amostras foi analisado, 209 na primeira etapa, antes da capacitação dos feirantes, e 50 na segunda, após qualificação dos feirantes em BPF. Das tortas doces recolhidas antes do treinamento dos feirantes, $65,6 \% ; 20,6 \%$ e $16,8 \%$ foram consideradas impróprias para o consumo por conter coliformes termotolerantes, Estafilococos coagulase positiva e Bacillus cereus acima do limite preconizado, respectivamente. Nas amostras recolhidas após o treinamento, observou-se uma melhora nas percentagens de contaminação encontradas (28,0\% continham coliformes termotolerantes, $14,0 \%$ contagem de Estafilococos coagulase positiva, e 28,0\% contagem de Bacillus cereus, todos acima do limite estabelecido). Nenhuma amostra apresentou Salmonella sp em ambas as etapas. Pode-se concluir que com o treinamento dos feirantes houve uma melhora na qualidade microbiológica destes produtos. Estes resultados reforçam a necessidade de treinamento dos feirantes e o impacto que pode ter na qualidade dos produtos. As temperaturas de conservação das tortas variaram de $-5,3^{\circ} \mathrm{C}$ a $28,7^{\circ} \mathrm{C}$ na $1^{\mathrm{a}}$ etapa e de $-3,6^{\circ} \mathrm{C}$ a $24,0^{\circ} \mathrm{C}$ na segunda. A presença do balcão refrigerado não foi suficiente para manter a temperatura ideal $\left(\right.$ até $\left.10^{\circ} \mathrm{C}\right)$ para a conservação das tortas doces.

Palavras-chave: Contaminação, alimentos, qualidade microbiológica
\end{abstract}

\footnotetext{
${ }^{1}$ Prof. Dr. do Centro de Pesquisa em Alimentos da Escola de Veterinária e Zootecnia da Universidade Federal de Goiás, UFG, Goiânia, GO. E-mail: rena@cpa.vet.ufg.br

${ }^{2}$ Discente do Curso de Pós-Graduação em Ciência e Tecnologia de Alimentos da Universidade Federal de Goiás, UFG, Goiânia, GO. E-mail: nayana.ea@ hotmail.com

${ }^{3}$ Discentes do Curso de Pós-Graduação em Zootecnia do Instituto Federal Goiano, Campus Rio Verde, GO. E-mail: jullyanecarvalho@hotmail.com; beatrizs.engal@gmail.com

${ }^{4}$ Prof. Dr. do Programa de Pós-Graduação em Zootecnia do Instituto Federal Goiano, Campus Rio Verde, GO. E-mail: marcotonyrv@yahoo.com.br

${ }^{5}$ Mestre em Ciência Animal pela Escola de Veterinária e Zootecnia, da Universidade Federal de Goiás, UFG, Goiânia, GO. E-mail: sheylaocavalcanti@hotmail.com

* Autor para correspondência
} 


\begin{abstract}
The sweet pies are widely consumed in special fairs in Goiânia-GO city. In general they are marketed in inadequate way, without refrigeration and most of times without any protection against various types of contaminants, including microbial contamination that can cause food toxi-infections to consumers. This study aimed to evaluate the microbiological quality of pies sold in 105 stalls in 23 special fair city of Goiânia, and also the impact of training on the Good Manufacturing Practices (GMP) in the quality of these products. The micro-organisms investigated were those required the by standard microbiological: Salmonella, fecal coliforms, Bacillus cereus and Staphylococcus coagulase positive. We also observed the temperature exposure of these foods on newsstands. We analyzed 259 samples in total, with 209 in the first stage, before the training of the fairground, and 50 in the second, after qualifying for the fair dealers in GMP. Pies sweets collected before training of fair dealers were considered unfit for consumption because it contains health indicators above the recommended limit $(65.6 \%$ with fecal coliforms, $20.6 \%$ Staphylococcus coagulase positive and $16.8 \%$ with Bacillus cereus). In samples collected after training there was an improvement in the indices (28,0\% contained coliforms, $14,0 \%$ Staphylococcus coagulase positive and $28,0 \%$ of Bacillus cereus, all above the limit set). None samples had Salmonella in both steps. It can be concluded that with the training of fair dealers there was an improvement in the microbiological quality of these products. These results reinforce the need for training of the fairground and the impact it can have on the quality of the products. The storage temperatures pies ranged from $-5.3^{\circ} \mathrm{C}$ to $28.7^{\circ} \mathrm{C}$ in first step and $-3.6^{\circ} \mathrm{C}$ to $24.0^{\circ} \mathrm{C}$ in the second. The presence of the refrigerated was not sufficient to maintain the optimal temperature (to $10^{\circ} \mathrm{C}$ ) for storage of pies.
\end{abstract}

Key words: Contamination, food, microbiological quality

\section{Introdução}

O número de vendedores ambulantes que comercializam ou preparam alimentos nas cidades brasileiras tem aumentado nos últimos anos (SOTO et al., 2008). Na cidade de Goiânia - Goiás existe uma grande diversidade e a quantidade de alimentos comercializados em vias públicas, especialmente em feiras especiais onde há predominância da venda de alimentos processados. As feiras especiais diferem das feiras tradicionais ou livres, pois estas últimas comercializam produtos "in natura" como frutas, verduras e carnes em geral.

As feiras especiais foram criadas há aproximadamente 24 anos como uma alternativa de fonte de renda e lazer para a população goianiense. Dentre as inúmeras variedades de alimentos fabricados pelos próprios feirantes e comercializados nas feiras especiais, destaca-se: churrascos, salgados, pizzas, sanduíches e tortas doces de recheios diversos. No entanto, a maioria dessas tortas é comercializada sem refrigeração e proteção alguma contra poeiras, insetos e outras fontes de contaminação, o que pode, consequentemente alterar a qualidade microbiológica e comprometer a saúde dos consumidores.
As precárias condições higiênico-sanitárias durante o preparo, transporte e exposição dos alimentos nas feiras especiais, bem como a manutenção dos produtos sob temperatura inadequada, são fatores que propiciam a contaminação por micro-organismos causadores de toxinfecções alimentares.

Os micro-organismos estão intimamente associados com a disponibilidade, a abundância e a qualidade dos produtos para consumo humano, esses alimentos são facilmente contaminados durante a manipulação e o processamento (CUNHA; SILVA, 2006).

Devido ao alto grau de perecibilidade das tortas doces, do elevado consumo desses produtos e, dos possíveis danos que podem causar à saúde devido a possibilidade de contaminação nas sucessivas etapas do processamento e conservação, torna-se importante adotar medidas preventivas que garantam maior segurança aos consumidores. Para Beiró e Silva (2009), os alimentos podem ser frequentemente associados a surtos de Doenças Transmitidas por Alimentos (DTA), sendo necessário um controle higiênico-sanitário adequado. 
Para evitar ou reduzir os riscos de DTA, medidas preventivas e de controle, incluindo as Boas Práticas de Fabricação (BPF), devem ser adotadas na cadeia produtiva, nos serviços de alimentação, nas unidades de comercialização de alimentos e nos domicílios, visando à melhoria das condições sanitárias dos alimentos (BRASIL, 2005).

Diante do exposto o objetivo da presente pesquisa foi avaliar a qualidade microbiológica de tortas doces de sabores diversos comercializadas nas feiras especiais da cidade de Goiânia - GO, em duas etapas: antes e após a capacitação aos feirantes em BPF.

\section{Material e Métodos}

\section{Caracterização das feiras e feirantes}

A coleta das amostras de tortas doces foi realizada em 105 bancas existentes nas 23 feiras especiais do município de Goiânia - GO. Os dias de funcionamento ocorreram nos períodos de terça a domingo entre as 15:00 e 22:00 horas. As feiras estão sujeitas às fiscalizações sanitárias rotineiras. Os bairros onde são realizadas as feiras incluem tanto os da região central e regiões consideradas mais nobres, quanto os de áreas mais afastadas e periféricas. As bancas são padronizadas, pois possuem duas grades de madeira para suportar as mercadorias, armação metálica e cobertura de lona. O suprimento de água é feito pelo acondicionamento em galões providenciados pelos próprios feirantes. Não existem nessas feiras instalações sanitárias, tão pouco pias para higienização de mãos.

Foi observado que das 105 bancas participantes no inicio da pesquisa, apenas 13 possuíam balcão refrigerado para o acondicionamento das tortas, duas mantinham os alimentos sobre placas de gelo e 77 não tinham dispositivo algum de refrigeração. Quanto ao transporte dos alimentos 90 feirantes afirmaram fazê-lo em veículo de passeio, apenas acondicionando as tortas em caixas de isopor, papelão ou vitrines de vidro. Apenas um feirante possuía veículo apropriado e específico para essa finalidade e os demais não relataram a forma de transporte.

\section{Amostragem}

O trabalho foi constituído de duas etapas. $\mathrm{Na}$ primeira etapa, realizada de agosto a junho de 2004 foram analisadas 209 amostras de tortas doces coletadas em todas as bancas das 23 feiras especiais de Goiânia, antes do treinamento BPF ofertado pela Vigilância Sanitária Municipal de Goiânia. O número de amostras foi estabelecido em função da quantidade de bancas (105) existentes, que apresentavam estes alimentos expostos à venda. Foram coletados dois sabores de tortas em cada banca, exceto uma onde houve a coleta de apenas um sabor.

A segunda etapa do trabalho foi realizada nos meses de fevereiro e março de 2006, após 24 meses da primeira fase (período necessário para a capacitação). Nessa etapa foram coletadas 50 amostras de 25 locais cujos feirantes participaram do treinamento BPF e que apresentaram resultados das amostras analisadas na primeira etapa (antes do treinamento BPF) insatisfatórios, ou seja, em desacordo com a Resolução RDC nº12/2001/ ANVISA/MS (BRASIL, 2001). Dentre os 25 feirantes, apenas cinco possuíam algum meio de refrigeração das tortas doces nas feiras especiais.

\section{Coletas das amostras}

Em cada banca foram coletados, nas duas etapas do trabalho, dois sabores de tortas, principalmente as de morango e de prestígio por conterem em suas composições ingredientes perecíveis, e também, por serem tipos de tortas encontradas na grande maioria das bancas. Na ausência destes sabores foram coletadas amostras de outros sabores de frutas, que continham basicamente os mesmos ingredientes na formulação. 
Nos pontos de venda, as coletas foram realizadas conforme as recomendações do Instituto Adolfo Lutz (IAL, 2008), com a retirada de uma fatia de aproximadamente 200 gramas do centro de cada amostra. As facas e espátulas utilizadas para o corte, bem como as caixas de isopor para acondicionar as amostras foram fornecidas pelo feirante para que houvesse semelhança com as condições de venda ao consumidor.

A temperatura foi verificada no centro geométrico das tortas em todas as etapas, com a introdução de termômetro de haste metálica da marca Incoterm ${ }^{\circledR}$, aferido para temperaturas de $-50^{\circ} \mathrm{C}$ a $120^{\circ} \mathrm{C}$, previamente higienizado com álcool 70,0\%. Após o acondicionamento em caixas de isopor, as amostras foram lacradas individualmente em sacos plásticos com lacres enumerados, acondicionadas em recipientes térmicos contendo gelo reciclável e mantidas sob refrigeração até o encaminhamento ao laboratório onde foram submetidas às análises microbiológicas.

\section{Análises laboratoriais e locais de realização}

A Resolução nº12/ 2001 (BRASIL, 2001) em seu item 18 subitem b: "bolos, tortas e similares, doces ou salgados, com ou sem recheio e cobertura, refrigerados ou congelados", preconiza as seguintes análises microbiológicas: Contagens de Estafilococos coagulase positiva, Bacillus cereus e de Coliformes a $45^{\circ} \mathrm{C}$ (ou termotolerantes) e Pesquisa de Salmonella sp.

As amostras coletadas na primeira etapa foram analisadas no Laboratório Central de Saúde Pública Dr. Giovanni Cysneiros (LACENGO) de acordo com métodos descritos por Silva, Junqueira e Silveira (2001) recomendados pelo American Public Health Association (APHA, 2001) Foram utilizadas as técnicas de Número Mais Provável para Estafilococos coagulase positiva e Coliformes termotolerantes.
As amostras coletadas na segunda etapa foram analisadas no Laboratório de Microbiologia do Centro de Pesquisa em Alimentos da Escola de Veterinária e Zootecnia da Universidade Federal de Goiás (CPA/EVZ/UFG), segundo os métodos analíticos oficiais descritos na Instrução Normativa $n^{\circ}$ 62/2003/MAPA (BRASIL, 2003) e as recomendações do APHA (2001) utilizando às técnicas de plaqueamento seletivo em ágar para Estafilococos coagulase positiva e Coliformes termotolerantes. Em ambas as etapas, as técnicas para pesquisa de Salmonella sp e contagem de Bacillus cereus foram as mesmas conforme APHA (2001).As análises foram comparadas levando em consideração o resultado de insatisfatório ou satisfatório, e o valor máximo aceitável específico para cada micro-organismo, de acordo com a legislação (Resolução RDC no 12/ 2001 ANVISA/ MS).

\section{Análise Estatística}

Foi empregada análise estatística descritiva e distribuição de frequência, análise de correlação e comparações entre média utilizando o teste de Quiquadrado $\left(\chi^{2}\right)$ e o teste $t$ (COCHRAN; COX, 1968; PIMENTEL GOMES, 1985 e CENTENO, 1999).

Antes de proceder à análise estatística dos resultados obtidos, as diversas variáveis amostrais em estudo foram testadas quanto ao seu padrão de distribuição, normal ou não (teste de normalidade de Kolmogorov-Smirnov) e em outros padrões descritivos (igualdade de variância e coeficiente de viés e curtose) (VANZOLINI, 1993). Como as variáveis amostrais apresentaram distribuição gaussiana, os resultados foram analisados utilizandose testes paramétricos (CENTENO, 1999).

Utilizou-se o teste $t$ de Student para variâncias equivalentes, excetuando-se os casos em que a análise das variáveis diferiram mais de quatro vezes, sendo nesse caso utilizado teste $t$ para variâncias diferentes. Foram consideradas estatisticamente 
significativas as diferenças entre variáveis comparadas quando a probabilidade bi-caudal da sua ocorrência devida ao acaso, mostrou-se menor ou igual a $5,0 \%(\mathrm{P} \leq 0,05)$.

A correlação entre duas variáveis foi calculada a fim de mostrar se a variação de uma delas acompanhou proporcional ou inversamente a variação da outra, como por exemplo temperatura $\mathrm{x}$ qualidade.

\section{Resultados e Discussão}

Resultados da qualidade bacteriológica das tortas doces coletadas em feiras especiais de Goiânia-GO

Todas as amostras estudadas apresentaram resultado negativo para pesquisa de Salmonella $\mathrm{sp}$ em $25 \mathrm{~g}$ de amostra. Este fato pode ser explicado por se tratar de micro-organismo facilmente controlado pela temperatura (exposição a $66^{\circ} \mathrm{C}$ por um minuto). A pressão osmótica exercida pela alta concentração de açúcar pode também ter sido um fator que dificultou o desenvolvimento deste tipo de micro-organismo. $\mathrm{O}$ mesmo resultado foi detectado por Carneiro, Gonçalves e Hoffmann (2005), ao analisarem 10 amostras de bombas de chocolate. Todas foram consideradas em conformidade com os padrões estabelecidos pela legislação para Salmonella sp.

Os resultados das análises de comparação da qualidade de tortas doces coletadas em feiras especiais da cidade de Goiânia - GO, na primeira e segunda etapa, antes e após o treinamento em BPF estão apresentados na Tabela 1. Das 209 tortas analisadas na $1^{\mathrm{a}}$ etapa, $154(73,7 \%)$ foram consideradas impróprias e 55 (26,3\%) próprias para o consumo humano. Por outro lado, das 50 tortas analisadas na segunda etapa $25(50,0 \%)$ foram consideradas impróprias para o consumo.

Para os coliformes termotolerantes foi encontrada diferença significativa $(\mathrm{P}<0,01)$ entre as etapas 1 e 2, indicando que há variabilidade entre estas etapas. Para estafilococos coagulase positiva pode-se observar uma não significância $(\mathrm{P}>0,05)$ em relação às duas etapas distintas, ocorrendo o mesmo para Bacillus cereus $(\mathrm{P}>0,05)$.

Em relação aos coliformes termotolerantes o número de amostras satisfatórias, coletadas na segunda etapa, foi de $72,0 \%$, um número maior que as analisadas na primeira etapa em que apenas $34,5 \%$ estavam próprias para o consumo, o que confirma o impacto positivo do treinamento sobre a qualidade das tortas quanto à contagem de coliformes termotolerantes. Para o Estafilococos coagulase positiva, embora tenha sido observada uma melhora na qualidade das tortas de 6,6\% quando são comparados os dados da primeira com a segunda etapa, não houve diferença estatística significativa entre elas, conforme mostrado na Tabela 1.

Em estudo com cinco feiras livres que comercializavam doce de leite na cidade de Pelotas, Rio Grande do Sul, Destri et al. (2009) constataram que $100 \%$ das amostras analisadas não apresentaram contaminação pelos micro-organismos: Salmonella, Coliformes a $45^{\circ} \mathrm{C}$ e Estafilococos coagulase positiva, o que evidencia aspectos positivos para a cidade e para a população consumidora local. Os resultados desta pesquisa indicam que as medidas higiênicas adequadas, durante o processamento de alimentos devem ser adotadas.

Com relação a Bacillus cereus, em ambas as etapas o percentual de amostras consideradas satisfatórias foi superior ao de insatisfatórias (Tabela 1). Embora, na segunda etapa, o número de amostras insatisfatórias tenha sido maior, a diferença entre as etapas não foi considerada significativa segundo o teste do Qui-quadrado. O treinamento em BPF não foi eficaz na redução da contaminação pelo Bacillus cereus, isto pode ser explicado pelo fato de se tratar de um micro-organismo esporulado de difícil eliminação, presente no ambiente e que pode se desenvolver, inclusive, sob baixas temperaturas.

Peixoto, Weckwerh e Simionato (2009) em avaliação à qualidade microbiológica de produtos 
de confeitaria comercializadas em Ribeirão Preto - São Paulo, verificaram que a contagem de Estafilococos coagulase positiva atendeu ao padrão microbiológico estabelecido pela legislação em amostras de doces a base de creme, mas $27,6 \%$ dos resultados apresentaram coliformes termotolerantes acima do estabelecido estando, portanto, impróprias para o consumo. Quanto a contagem de B. cereus e Salmonella não foram detectadas a presença.

Tabela 1. Comparação da qualidade de tortas doces coletadas em feiras especiais da cidade de Goiânia - GO, antes e após o treinamento em BPF, segundo o teste de $\chi^{2}$.

\begin{tabular}{|c|c|c|c|c|}
\hline \multicolumn{5}{|c|}{ Coliformes termotolerantes } \\
\hline & \multirow{2}{*}{ Etapa } & \multicolumn{2}{|c|}{ Condição da amostra } & \multirow{2}{*}{ Total } \\
\hline & & Insatisfatório & Satisfatório & \\
\hline Primeira & & $137,0(121,9)^{1}$ & $72,0(87,2)$ & 209 \\
\hline Segunda & & $14,0(29,2)$ & $36,00(20,9)$ & 50 \\
\hline Total & & 151,0 & 108,0 & 259 \\
\hline Teste $\chi^{2}$ & & 23,4 & & - \\
\hline $\mathrm{P}_{\text {valor }}$ & & $<0,0001$ & & - \\
\hline \multicolumn{5}{|c|}{ Estafilococos coagulase positiva } \\
\hline & \multirow{2}{*}{ Etapa } & \multicolumn{2}{|c|}{ Condição da amostra } & \multirow{2}{*}{ Total } \\
\hline & & Insatisfatório & Satisfatório & \\
\hline Primeira & & $43,0(40,4)$ & $166,0(168,6)$ & 209 \\
\hline Segunda & & 7,0 & $43,0(40,4)$ & 50 \\
\hline Total & & 50,0 & 209,0 & 259,0 \\
\hline Teste $\chi^{2}$ & & 1,1 & & - \\
\hline $\mathrm{P}_{\text {valor }}$ & & 0,3 & & - \\
\hline \multicolumn{5}{|c|}{ Bacillus cereus } \\
\hline & \multirow{2}{*}{ Etapa } & \multicolumn{2}{|c|}{ Condicão da amostra } & \multirow{2}{*}{ Total } \\
\hline & & Insatisfatório & Satisfatório & \\
\hline Primeira & & $35,0(39,5)$ & $174,0(169,5)$ & 209 \\
\hline Segunda & & $14,0(9,5)$ & $36,0(40,5)$ & 50 \\
\hline Total & & 49,0 & 210,0 & 259 \\
\hline Teste $\chi^{2}$ & & 2,4 & & - \\
\hline $\mathrm{P}_{\text {valor }}$ & & 0,1 & & - \\
\hline \multicolumn{5}{|c|}{ Conclusão $^{2}$} \\
\hline \multirow{2}{*}{\multicolumn{2}{|c|}{ Etapa }} & \multicolumn{2}{|c|}{ Condição da amostra } & \multirow{2}{*}{ Total } \\
\hline & & Insatisfatório & Satisfatório & \\
\hline Primeira & & $154,0(144,4)$ & $55,0(64,6)$ & 209 \\
\hline Segunda & & $25,0(34,5)$ & $25,00(15,4)$ & 50 \\
\hline Total & & 179,0 & 80,0 & 259 \\
\hline Teste $\chi^{2}$ & & 10,6 & & - \\
\hline$P_{\text {valor }}$ & & 0,0011 & & - \\
\hline
\end{tabular}

1- Valores referentes às frequências esperadas

2- Situação do produto levando-se em consideração os quatro micro-organismos (Salmonella sp ausente em todas as amostras)

Fonte: Elaboração dos autores. 
Pesquisa realizada em 23 restaurantes de autosserviço da cidade de Itumbiara - GO, que forneciam alimentos do tipo: macarronada, salada de tomate e pepino, maionese e carne de panela, observou-se que apenas um dos estabelecimentos não apresentou contaminação acima do padrão permitido pela Resolução RDC 12 (BRASIL, 2001), para mesófilos totais, Estafilococos coagulase positiva e coliformes termotolerantes, entretanto 16 $(69,6 \%)$ estabelecimentos apresentaram pelo menos três tipos de alimentos com contagem acima do recomendado, o que demonstra a baixa qualidade higiênico-sanitária durante o preparo dos alimentos. Após o minicurso sobre BPF, no entanto, observouse que as amostras coletadas de 20 locais avaliados na segunda etapa, estavam de acordo com a legislação apresentando uma diferença estatisticamente significante $(\mathrm{p} \leq 0,05)$ na comparação dos níveis de contaminação microbiológica dos alimentos antes e após o treinamento (DOLINGER et al., 2010).

O mesmo fato foi observado por Farias, Pereira e Figueiredo (2011), em uma unidade hospitalar no Pará antes e após o treinamento sobre boas práticas, verificando melhoria no local em relação às análises microbiológicas realizadas no segundo período de avaliação, os resultados mostraram conformidade à legislação vigente e adequabilidade das amostras ao consumo humano, demonstrando-se a importância do treinamento sobre a higiene e a aplicação das BPF.

Alguns parâmetros de tendência central referentes à média aritmética, moda e valores máximos e mínimos encontrados para cada microorganismo também foram estudados. Estas medidas não foram comparadas entre as etapas 1 e 2 por serem de unidades distintas (NMP/g e UFC/g). Estes resultados podem ser observados na Tabela 2. Pode-se observar que para a variável coliformes termotolerantes, o valor máximo encontrado na $1^{\mathrm{a}}$ etapa foi de $2400 \mathrm{NMP} / \mathrm{g}$, já na $2^{\mathrm{a}}$ etapa foi de $2,4 \times 10^{6} \mathrm{UFC} / \mathrm{g}$ com moda de $4,5 \times 10^{2} \mathrm{UFC} / \mathrm{g}$.
Para Estafilococos coagulase positiva a maior contagem encontrada na $1^{\text {a }}$ etapa foi de 2400 $\mathrm{NMP} / \mathrm{g}$ e na $2^{\mathrm{a}}$ etapa, de $4,9 \times 10^{4} \mathrm{UFC} / \mathrm{g}$, resultados superiores aos padrões exigidos pela RDC 12/2001 $\left(10^{3} \mathrm{UFC} / \mathrm{g}\right)$. As tortas doces coletadas nas feiras não apresentaram contagens de Estafilococos coagulase positiva acima de $10^{5} \mathrm{UFC} / \mathrm{g}$ considerada como valor mínimo para haver produção de enterotoxina capaz de causar intoxicação alimentar, mas nem por isso representam um menor risco à saúde dos consumidores (ICMSF, 1983). Com relação a Bacillus cereus, a contagem máxima na $1^{\mathrm{a}}$ etapa foi bem inferior à da $2^{\mathrm{a}}$ etapa $\left(1,0 \times 10^{3} \mathrm{UFC} / \mathrm{g}\right.$ e $3,6 \times 10^{5}$ $\mathrm{UFC} / \mathrm{g}$, respectivamente) e a moda de $1,0 \times 10^{3}$ $\mathrm{UFC} / \mathrm{g}$ na $1^{\mathrm{a}}$ etapa e $1,0 \times 10^{4} \mathrm{UFC} / \mathrm{g}$ na $2^{\mathrm{a}}$ etapa, sendo que esta contagem máxima é considerada elevada e preocupante.

Costa et al. (2009), estudando o perfil microbiológico de 196 amostras diferentes de alimentos comercializados em feiras de GoiâniaGO constataram que 22 amostras apresentaram contagem acima dos padrões permitidos pela legislação sanitária por pelo menos um dos microorganismos avaliados: Coliformes a $45^{\circ} \mathrm{C} / \mathrm{g}$, Estafilococos coagulase positiva e Bacillus cereus, sendo que tais resultados podem implicar em riscos a saúde dos consumidores.

Na pesquisa de Carneiro, Gonçalves e Hoffmann (2005), com bombas de chocolate foram observados que $100 \%$ das amostras analisadas apresentaram conformidade com as especificações estabelecidas pela legislação para coliformes termotolerantes, tendo sido encontrados valores $<3$ a $93 \mathrm{NMP} / \mathrm{g}$, já a determinação de Estafilococos coagulase positiva e Bacillus cereus resultou em $<100$ a 2,1x106 UFC/g. Resultados superiores aos padrões normativos exigidos. 
Tabela 2. Dados relativos a estatística descritiva dos resultados bacteriológicos de tortas doces em feiras especiais nas etapas 1 e 2.

\begin{tabular}{|c|c|c|c|c|}
\hline \multicolumn{5}{|c|}{ Coliformes termotolerantes } \\
\hline \multirow{2}{*}{ Parâmetros } & \multicolumn{2}{|c|}{ Etapa $1(\mathrm{NMP} / \mathrm{g})$} & \multicolumn{2}{|c|}{ Etapa 2 (UFC) } \\
\hline & $<=100$ & $>100$ & $<=100$ & $>100$ \\
\hline Freq. Abs & 72,0 & 137,0 & 36,0 & 14,0 \\
\hline Freq. Rel. (\%) & 34,5 & 65,6 & 72,0 & 28,0 \\
\hline Média & 24,7 & 1745,8 & 54,7 & 201338,0 \\
\hline Moda & 3,0 & 2400,0 & 100,0 & 450,0 \\
\hline Máximo & 93,0 & 2400,0 & 100,0 & 2400000,0 \\
\hline Mínimo & 1,0 & 110,0 & 9,0 & 150,0 \\
\hline \multicolumn{5}{|c|}{ Estafilococos coagulase positiva } \\
\hline \multirow{2}{*}{ Parâmetros } & \multicolumn{2}{|c|}{ Etapa $1(\mathrm{NMP} / \mathrm{g})$} & \multicolumn{2}{|c|}{ Etapa 2 (UFC) } \\
\hline & $<=1000$ & $>1000$ & $<=1000$ & $>1000$ \\
\hline Freq. Abs & 166 & 43 & 43,0 & 7,0 \\
\hline Freq. Rel. (\%) & 79,4 & 20,6 & 86,0 & 14,0 \\
\hline Média & 37,2 & 2400,0 & 298 & 11357,1 \\
\hline Moda & 3,0 & 2400,0 & 9,0 & Amodal \\
\hline Máximo & 240,0 & 2400,0 & 1000,0 & 49000,0 \\
\hline Mínimo & 0,0 & 2400,0 & 9,0 & 2000,0 \\
\hline \multicolumn{5}{|c|}{ Bacillus cereus } \\
\hline \multirow{2}{*}{ Parâmetros } & \multicolumn{2}{|c|}{ Etapa $1(\mathrm{NMP} / \mathrm{g})$} & \multicolumn{2}{|c|}{ Etapa 2 (UFC) } \\
\hline & $<=1000$ & $>1000$ & $<=1000$ & $>1000$ \\
\hline Freq. Abs & 174,0 & 35,0 & 36,0 & 14,0 \\
\hline Freq. Rel. (\%) & 83,3 & 16,8 & 72,0 & 28,0 \\
\hline Média & 3,4 & 1001,0 & 253,4 & 54066,7 \\
\hline Moda & 3,0 & 1001,0 & 9,0 & 10000,0 \\
\hline Máximo & 16,0 & 1001,0 & 1000,0 & 360000,0 \\
\hline Mínimo & 0,0 & 1001,0 & 9,0 & 1001,0 \\
\hline
\end{tabular}

Fonte: Elaboração dos autores.

A simples presença do Bacillus cereus revela a necessidade de intervenções durante o processamento e armazenamento, devido ao potencial de multiplicação ao ser transferido aos alimentos, podendo colocar em risco a saúde da população (COELHO et al., 2010). Em contagens baixas pode haver um número de células vegetativas de B.cereus e/ou toxinas pré-formadas de Estafilococos coagulase positiva suficientes para causar toxinfecção/intoxicação alimentar, por isso as BPFs devem ser uma preocupação constante dos feirantes/manipuladores para fornecerem os alimentos sempre próprios para o consumo.
Ao contrário da Salmonella sp que é eliminada facilmente através da cocção, o Bacillus cereus cresce bem em alimentos cozidos devido à inativação da microbiota competidora. Fonseca et al. (2005) afirmaram que o Bacillus cereus é uma bactéria que se desenvolve em baixas temperaturas (inferiores a $10^{\circ} \mathrm{C}$ ) e é de difícil eliminação por estar presente no ambiente. As feiras especiais são excelentes locais para a disseminação pela presença de poeira, fumaça e todo tipo de contaminação externa. Por este motivo, o principal método de controle é a prevenção da germinação de esporos e da multiplicação em alimentos cozidos prontos para o consumo através de refrigeração adequada. 
Resultados das temperaturas de conservação das tortas doces coletadas em feiras especiais de Goiânia-GO

Com relação à temperatura de conservação das tortas, observa-se na Tabela 3 um resultado não significativo $(\mathrm{P}>0,05)$ entre os valores médios das duas etapas. A temperatura média na etapa 1 $\left(15,8^{\circ} \mathrm{C}\right)$ foi menor que a temperatura média na etapa $2\left(16,2^{\circ} \mathrm{C}\right)$, porém ambas as temperaturas estavam além da temperatura ideal recomendada para conservação de alimentos (até $10^{\circ} \mathrm{C}$ ). Este resultado já era esperado, haja visto o pequeno número de feirantes que possuíam algum meio de refrigeração das tortas nas feiras (13 feirantes na primeira etapa e cinco na segunda).

Tabela 3. Comparação entre médias de temperatura de tortas doces comercializadas em feiras especiais de Goiânia segundo teste $t$ de Student, antes e após o treinamento em BPF.

\begin{tabular}{lccc}
\hline & \multicolumn{2}{c}{ Temperatura } & \\
\hline Etapa & Média & Desvio padrão & $\mathrm{N}$ \\
\hline Primeira & 15,8 & 5,8 & 209 \\
Segunda & 16,2 & 6,2 & 50 \\
Teste t & 0,2 & & - \\
$\mathrm{P}_{\text {valor }}$ & 0,6 & & - \\
\hline
\end{tabular}

Fonte: Elaboração dos autores.

A Tabela 4 mostra as diversas temperaturas verificadas nas tortas doces segundo os níveis de classificação: inferior a $0^{\circ} \mathrm{C}$, entre $0^{\circ} \mathrm{C}$ e $10^{\circ} \mathrm{C}$, entre $10^{\circ} \mathrm{C}$ e $20^{\circ} \mathrm{C}$ e acima de $20^{\circ} \mathrm{C}$. Com relação à temperatura de armazenamento de tortas doces foram observados valores extremos variando de $-5,3^{\circ} \mathrm{C}$ a $28,7^{\circ} \mathrm{C}$ na etapa 1 , na etapa 2 os valores variaram de $-3,6^{\circ} \mathrm{C}$ a $24,0^{\circ} \mathrm{C}$. Na primeira etapa das coletas apenas três amostras apresentaram temperatura inferior a $0^{\circ} \mathrm{C}$, com valor médio de $-3,9^{\circ} \mathrm{C}$ e o mínimo de $-5,3^{\circ} \mathrm{C}$ para tortas de um feirante sem balcão refrigerado cujo resultado foi insatisfatório, com presença de coliformes termotolerantes além do padrão.

Tabela 4. Temperaturas verificadas nas tortas doces segundo as etapas e intervalos de classe.

\begin{tabular}{ccccccccc}
\hline \multicolumn{1}{c}{ Temperatura } \\
\hline \multirow{2}{*}{ Parâmetros } & \multicolumn{9}{c}{$1^{\mathrm{a}}$ Etapa $\left({ }^{\circ} \mathrm{C}\right)$} \\
\cline { 2 - 8 } & $<0$ & $0-10$ & $10-20$ & $>20$ & $<0$ & $0-10$ & $10-20$ & $>20$ \\
\hline Freq. Abs & 3,0 & 27,0 & 134,0 & 45,0 & 2,0 & 6,0 & 28,0 & 14,0 \\
Freq. Rel (\%) & 1,4 & 12,9 & 64,1 & 21,5 & 4,0 & 12,0 & 56,0 & 28,0 \\
Média & $-3,9$ & 6,1 & 15,6 & 22,6 & $-2,9$ & 6,6 & 17 & 21,6 \\
Moda & Amodal & 9,5 & 13,7 & 20,0 & Amodal & Amodal & 14,3 & 22,0 \\
Máximo & $-2,3$ & 9,8 & 20,0 & 28,7 & $-2,2$ & 9,0 & 20,0 & 24,0 \\
Mínimo & $-5,3$ & 0,6 & 10,5 & 20,0 & $-3,6$ & 3,6 & 12,0 & 20,3 \\
\hline
\end{tabular}

Fonte: Elaboração dos autores. 
$\mathrm{Na}$ segunda etapa das coletas duas amostras estavam acondicionadas sob temperatura inferior a $0^{\circ} \mathrm{C}$, com a mínima de $-3,6^{\circ} \mathrm{C}$ para a torta de um feirante que não possuía balcão refrigerado. Ambas as amostras foram consideradas próprias para o consumo. $\mathrm{Na}$ faixa de temperatura ideal de acondicionamento de alimentos perecíveis entre $0^{\circ} \mathrm{C}$ e $10^{\circ} \mathrm{C}$, na primeira etapa apenas $12,9 \%$ das tortas (27 amostras) apresentaram-se adequadas, tendo sido a moda de $9,5^{\circ} \mathrm{C}$. Na segunda etapa o percentual foi semelhante: seis amostras $(12,0 \%)$ de 50 analisadas estavam dentro desta faixa ideal com valor mínimo de $3,6^{\circ} \mathrm{C}$ e máximo de $9,0^{\circ} \mathrm{C}$ e amodal.

Mais da metade das 209 amostras $(64,1 \%)$ apresentavam-se expostas à venda em temperaturas entre $10^{\circ} \mathrm{C}$ e $20^{\circ} \mathrm{C}$, armazenadas em balcões de refrigeração, sobre placas de gelo, vitrines de vidro ou expostas ao ambiente, tendo sido encontrada uma média de $15,6^{\circ} \mathrm{C}$ e uma moda de $13,7^{\circ} \mathrm{C}$ na primeira etapa. Este percentual elevado já era esperado pelo número pequeno de feirantes que possuem balcão refrigerado nas feiras. Já na segunda etapa, 56,0\% das amostras estavam dentro desta faixa, mostrando uma tendência de melhoria de 12,0\% com relação à primeira etapa. A média e a moda, no entanto se mantiveram praticamente sem alteração (Tabela 4).

Acima dos $20^{\circ} \mathrm{C}$, foram observadas $21,5 \%$ das amostras (45 amostras), tendo sido a temperatura mais elevada de $28,7^{\circ} \mathrm{C}$ em torta sabor morango de um feirante sem balcão refrigerado e com resultado insatisfatório para coliformes termotolerantes. $\mathrm{Na}$ segunda etapa o número de amostras nesta faixa também foi elevado: 28,0\% (14 amostras) apresentaram-se acondicionadas sob temperatura além da recomendada, com a máxima de $24,0^{\circ} \mathrm{C}$ para uma torta em uma feira livre que acondicionava fora do balcão e com níveis elevados de Bacillus cereus e coliformes termotolerantes.

Nas análises microbiológicas de Furlaneto e Kataoka (2004), com 10 amostras de lanches comercializados em carrinhos de ambulantes, foi encontrado em $100 \%$ das amostras contagem de coliformes totais, $90,0 \%$ coliformes fecais, $50,0 \%$ E. aureus e não foi detectada a presença de Salmonella sp, diante disso, observou-se que seis carrinhos não possuíam refrigerador e as matériasprimas permaneciam em temperatura ambiente por várias horas consecutivas, o que favorecem o desenvolvimento e multiplicação de microorganismos.

Bianchi et al. (2005) analisando 24 amostras de bombas recheadas, verificaram que $100 \%$ estavam acondicionadas sob temperatura acima de $10^{\circ} \mathrm{C}$, sendo que sete apresentaram temperaturas entre $10^{\circ} \mathrm{C}$ e $20^{\circ} \mathrm{C}$ e $17(78,0 \%)$, acima de $20^{\circ} \mathrm{C}$ com valor máximo encontrado de $33^{\circ} \mathrm{C}$. A Tabela 4 mostra, uma temperatura máxima mais elevada $\left(28,7^{\circ} \mathrm{C}\right)$, considerada temperatura ambiente de locais quentes, e também nenhuma amostra armazenada abaixo de $10^{\circ} \mathrm{C}$.

Analisando-se os dados mostrados na Tabela 4 pode-se inferir que os feirantes que mantinham suas tortas sob temperatura adequada de até $10^{\circ} \mathrm{C}$, conseguiram manter essa conservação. Aqueles que estavam na faixa intermediária apresentaram uma pequena melhora e aqueles que acondicionavam seus produtos acima de $20^{\circ} \mathrm{C}$ não conseguiram melhora alguma nesse aspecto.

Este resultado pode ser considerado preocupante, pois a refrigeração adequada é fator primordial na prevenção da produção de toxinas, porque prolonga a fase LAG de multiplicação bacteriana e as toxinas são produzidas na fase seguinte: LOG ou exponencial. Se o alimento permanece sob temperatura e tempo corretos de exposição, o desenvolvimento do micro-organismo é retardado, o que minimiza muito os riscos de intoxicação alimentar. Considerando este aspecto, é fundamental que os feirantes se adequem e encontrem meios de refrigeração eficientes capazes de manter as tortas sob temperatura de segurança.

Lopes, Madokoro e Martins (2010), avaliando a conservação de alimentos à venda em lanchonetes 
da UNICAMP, observaram que em relação aos bolos com coberturas, apenas a lanchonete denominada como três apresentou armazenamento inadequado, por deixar esses doces sobre bancadas e sem qualquer refrigeração, mas, apesar disso, não ofereciam riscos ao consumidor, visto que o consumo dos produtos é bastante rápido (em lanchonetes movimentadas).

Quando perguntados sobre o destino final das sobras de tortas não vendidas, 24 feirantes afirmaram que estas seriam consumidas em casa, 36 provavelmente iriam doar a vizinhos, 16 fariam doações a creches e igrejas, três distribuiriam para outras pessoas presentes na feira após o encerramento das atividades comerciais e 10 venderiam na feira do dia seguinte, sete afirmaram que não haveria sobras e 09 não souberam informar o destino das mesmas. Diante destas informações fica evidente o aumento do risco de possíveis surtos de intoxicações alimentares caso estas sobras de tortas sejam consumidas, especialmente por crianças, idosos, convalescentes, dentre outros.

Faria, Kopper e Lima (2009), estudando o destino das sobras suja e limpas em uma empresa fornecedora de refeições coletivas, constataram que as sobras de preparações quentes mantidas em espera, mesmo não atendendo aos critérios para serem consideradas sobras limpas, eram reutilizadas, e representavam um risco de multiplicação microbiana, uma vez que os resultados das análises microbiológicas das preparações indicaram contaminação por Estafilococos coagulase positiva para carnes. Para as amostras frias (saladas) foi encontrado crescimento para coliformes a $45^{\circ} \mathrm{C}$.

\section{Correlações entre as variáveis analisadas}

Não há dúvidas de que a refrigeração constitui um meio de controle de multiplicação microbiana extremamente eficiente, exercendo um efeito bacteriostático por prolongar a fase lag de multiplicação bacteriana. Porém, a correlação entre a temperatura das tortas doces e os resultados microbiológicos foi considerada baixa ou nula do ponto de vista estatístico, ou seja, houve pouca interferência da temperatura de conservação sobre a carga microbiana das amostras (Tabela 5).

Analisando a Tabela 5, verifica-se que há uma correlação baixa entre as variáveis na etapa 1 . Nesta etapa apenas os micro-organismos do grupo dos Coliformes termotolerantes e estafilococos coagulase positiva apresentaram uma correlação considerada mediana de $24,0 \%(\mathrm{r}=0,24$ e $\mathrm{P}<0,05)$. A correlação Coliformes $\mathrm{x}$ Bacillus cereus foi de apenas 14,0\% ( $\mathrm{r}=0,14$ e $\mathrm{P}<0,05)$ e de Estafilococos coagulase positiva $\mathrm{x}$ Bacillus cereus de apenas $9,0 \%$. A correlação temperatura x micro-organismos analisados foi baixa, chegando a ser negativa para coliformes termotolerantes $(-0,03)$ e $8,0 \%(0,08)$ e $5,0 \%(0,05)$ para Estafilococos coagulase positiva $\mathrm{x}$ Bacillus cereus, respectivamente.

Para a etapa 2 (representada pela parte inferior da diagonal azul - Tabela 5), a correlação Coliformes $\mathrm{x}$ Estafilococos coagulase positiva, chegou a ser negativa (-0,024), enquanto a correlação Coliformes $\mathrm{x}$ Bacillus cereus foi surpreendentemente alta $(\mathrm{r}=0,87 \mathrm{P}<0,01)$, pois não é conhecida esta correlação, e sim entre Coliformes termotolerantes e enterobactérias, em especial Salmonella sp e Shigella. A correlação Estafilococos coagulase positiva x Bacillus cereus continuou baixa $(5,0 \%)$. A temperatura nesta etapa também não exerceu forte influência sobre os resultados microbiológicos: $18,0 \%$ para coliformes, $11,0 \%$ para Bacillus cereus e negativa para Estafilococos coagulase positiva $(-0,26)$, o que também foi surpreendente. Deste modo, observa-se que a contaminação das tortas doces pode ter ocorrido aleatoriamente, ou seja, a ocorrência de um micro-organismo não aumentou ou diminuiu a ocorrência de outro, levando a inferir que a contaminação das tortas foi casual e esteve mais ligada ao manipulador, à matéria- prima e à higiene ambiental. 
Tabela 5. Matriz de correlação entre temperatura e os micro-organismos Estafilococos coagulase positiva e Bacillus cereus e o grupo coliformes termotolerantes, em tortas durante a etapa 1 (acima da diagonal azul) e etapa 2 (abaixo da diagonal azul) provenientes de feiras especiais de Goiânia.

\begin{tabular}{lcccccc}
\hline \multicolumn{1}{c}{ Variáveis } & Coliformes & $\begin{array}{c}\text { Estafilococos } \\
\text { coagulase } \\
\text { positiva }\end{array}$ & $\begin{array}{c}\text { Bacillus } \\
\text { cereus }\end{array}$ & $\begin{array}{c}\text { Temperatura } \\
\left({ }^{\circ} \mathrm{C}\right)\end{array}$ & Média $^{1}$ & $\begin{array}{c}\text { Desvio } \\
\text { Padrão }\end{array}$ \\
\hline Coliformes & & 0,2 & 0,1 & $-0,03$ & 1156,1 & 1119,7 \\
Estafilococos & $-0,024$ & & 0,1 & 0,1 & 523,5 & 960 \\
Bacillus cereus & 0,9 & 0,1 & & 0,1 & 174,7 & 377,4 \\
Temperatura & 0,2 & $-0,3$ & 0,1 & & 15,7 & 5,8 \\
Média $^{2}$ & 60439,7 & 1846,2 & 16382,4 & 16,2 & & - \\
Desvio Padrão $^{2}$ & 342547,3 & 7035,5 & 57277,8 & 6,2 & - & \\
\hline
\end{tabular}

1: referente a etapa $1 ; 2$ : referente a etapa 2.

Fonte: Elaboração dos autores.

De acordo com Battaglini et al. (2012) os manipuladores de alimentos são um dos principais transmissores de micro-organismos durante $o$ processamento dos alimentos, analisando as mãos de seis manipuladores, foi encontrada a presença de coliformes totais em cinco processadores de alimentos e a presença de Estafilococos aureu foi encontrada em dois $(35,0 \%)$, ambas as análises foram realizadas antes e durante o trabalho. Ferrari, Winker e Oliveira (2007) analisaram microbiologicamente alimentos isentos de registros no Ministério da Saúde e identificaram alguns produtos com contagem microbiana acima do permitido pela legislação brasileira, concluindo a necessidade de maior fiscalização das condições de preparo, manipulação e armazenagem dos diversos alimentos analisados.

Algumas amostras acondicionadas sob altas temperaturas apresentaram resultado satisfatório, enquanto outras acondicionadas sob temperaturas inferiores a $10^{\circ} \mathrm{C}$ foram consideradas impróprias para o consumo, o que comprova a correlação baixa entre temperatura $\mathrm{x}$ micro-organismo. $\mathrm{O}$ fato de amostras com temperaturas elevadas apresentarem baixo crescimento microbiano pode ocorrer caso as BPFs sejam seguidas durante todo o preparo das tortas, ou seja, boas condições higiênicas durante o processamento das mesmas. Se o alimento tiver uma carga microbiana inicial baixa, o tempo de exposição, caso não ultrapasse mais de duas horas sob temperatura inferior a $10^{\circ} \mathrm{C}$, irá dificultar a multiplicação dos micro-organismos. Por outro lado, caso o alimento apresente alto nível de contaminação, mesmo antes de ser exposto à venda, a refrigeração, por mais eficiente que seja, não será capaz de diminuir a carga microbiana e impedir a multiplicação rápida dos micro-organismos.

\section{Conclusões}

O percentual de amostras consideradas impróprias para o consumo por conter Coliformes termotolerantes, Estafilococos coagulase positiva e Bacillus cereus, acima do limite preconizado pela Legislação Brasileira, foi considerado elevado em ambas as etapas, o que representa um perigo a saúde dos consumidores. Nenhuma amostra analisada estava contaminada com Salmonella sp. Houve melhora na qualidade das tortas doces após o treinamento ministrado aos feirantes.

Houve baixa correlação entre a temperatura de acondicionamento das tortas doces e as contagens de Estafilococos coagulase positiva, Bacillus cereus e Coliformes termotolerantes. Em ambas as etapas, mais de $84,0 \%$ das amostras estavam acondicionadas em temperaturas superiores a $10^{\circ} \mathrm{C}$, o que aumenta 
o risco de multiplicação microbiana. Houve grande variabilidade nas temperaturas verificadas intra e entre feirantes, demonstrando a dificuldade em manter as tortas bem acondicionadas nas feiras.

\section{Referências}

AMERICAN PUBLIC HEALTH ASSOCIATION APHA. Compendium of methods for the microbiological examination of foods. Washington: APHA, 2001. $676 \mathrm{p}$.

BATTAGLINI, A. P. P.; FAGNANI, R.; TAMANINI, R.; BELOTI, V. Qualidade microbiológica do ambiente, alimentos e água, em restaurantes da Ilha do Mel/PR. Semina: Ciências Agrárias, Londrina, v. 33, n. 2, p. 741754, abr. 2012.

BEIRÓ, C. F. F.; SILVA, M. C. Análise das condições de higiene na comercialização de alimentos em uma feira livre do Distrito Federal. Universitas: Ciências da Saúde, Brasília, v. 7, n. 1, p. 13-28, 2009.

BIANCHI, M. C.; SOUZA, D. L.; SILVÉRIO, F. L.; OLIVEIRA, T. S.; GOLLUCKE, A. P. B. Ocorrência de estafilococos coagulase positivo em doces recheados vendidos em feiras livres. Revista Higiene Alimentar, Mirandópolis, v. 19, n. 132, p. 49-57, 2005.

BRASIL. Anvisa-Agencia Nacional de Vigilância da Saúde. Resolução RDC ANVS/MS nº 12, de 02 de janeiro de 2001. Regulamento técnico e princípios gerais para o estabelecimento de critérios e padrões microbiológicos para alimentos. Diário Oficial [da] União, Poder Executivo, Brasília, DF, 10 jan. 2001. Seção 1, p. 46-53. Ministério da Agricultura Pecuária e
Abastecimento. Instrução Normativa $\mathrm{n}^{\circ} 62$ de 26 de
agosto de 2003. Métodos analíticos oficiais para análises
microbiológicas para controle de produtos de origem
animal e água. Diário Oficial [da] União, Brasília, DF,
18 set. 2003. Seção 1, p. 14 .

. Ministério da Saúde. Secretaria de Atenção à Saúde. Coordenação-Geral da Política de Alimentação e Nutrição. Guia alimentar para a população brasileira: promovendo a alimentação saudável. Ministério da Saúde, Secretaria de Atenção à Saúde, CoordenaçãoGeral da Política de Alimentação e Nutrição. Brasília: Ministério da Saúde, 2005. 151 p. (Série A. Normas e Manuais Técnicos).

CARNEIRO, A. A. J.; GONÇALVES, T. M. V.; HOFFMANN, F. L. Estudo higiênico-sanitário de bombas de chocolate com recheio de creme. Revista Higiene Alimentar, Mirandópolis, v. 19, n. 128, p. 78-86, 2005.
CENTENO, A. J. Curso de estatística aplicada à biologia. Goiânia: Centro Editorial e Gráfico/UFG, 1999. $188 \mathrm{p}$.

COCHRAN, W. G.; COX, G. W. Experimental designs. New York: Wiley, 1968. 466 p.

COElHO, A. Í. M; MILAGRES, R. C. R. M.; MARTINS, J. F. L.; AZEREDO, R. M. C.; SANTANA, Â. M. C. Contaminação microbiológica de ambientes e de superfícies em restaurantes comerciais. Ciência \& Saúde Coletiva, Manguinhos, v. 15, p. 1597-1606, 2010. Suplemento 1.

COSTA, R. M.; REZIO, M. A.; SANTANA, R. G. M.; CARVALHO, B. A.; AGOSTINHO, T. M. S.; MONEGO, E. T.; CAMPOS, R. H. Perfil microbiológico de alimentos comercializados em feiras especiais de Goiânia, Goiás. Revista Higiene Alimentar, Mirandópolis, v. 23, n. 170171, p. 60-61, 2009.

CUNHA, M. A.; SILVA, M. R. Métodos de detecção de microorganisnos indicadores. Saúde \& Ambiente em Revista, Duque de Caxias, v. 1, n. 1, p. 09-13, jan./jun. 2006.

DESTRI, K.; BAIRROS, J.; VARGAS, B. L.; NASCENTE, P. S.; DEL PINO, F. A. B.; LUND, R. G. Análise microbiológica de doces de leite vendidos em feiras livres de Pelotas, Estado do Rio Grande do Sul. Acta Scientiarum. Biological Sciences, Maringá, v. 31, n. 2, p. 153-157, 2009.

DOLINGER, E. J. O. V.; MELO, P. C.; MORAIS, G. R.; SILVA, C. R. M.; BRITO, D. V. D. Contaminação microbiológica de alimentos comercializados em restaurantes de auto-serviço de Itumbiara-GO. Revista Biotemas, Florianópolis, v. 23, n. 4, p. 129-133, dez. 2010.

FARIA, C. P.; KOPPER, A. M.; LIMA, M. G. Avaliação da aplicação dos conceitos de sobras sujas e limpas em uma empresa fornecedora de refeições coletivas. Revista Higiene Alimentar, Mirandópolis, v. 23, n. 170-171, p. 30-31, 2009.

FARIAS, J. K. R.; PEREIRA, M. M. S.; FIGUEIREDO, E. L. Avaliação de boas práticas e contagem microbiológica das refeições de uma unidade de alimentação hospitalar, do município de São Miguel do Guamá - Pará. Alimentos e Nutrição, Araraquara, v. 22, n. 1, p. 113-119, jan./mar. 2011.

FERRARI, R. G.; WINKLER, S. M.; OLIVEIRA, T. C. R. M. Avaliação microbiológica de alimentos isentos de registro no Ministério da Saúde. Semina: Ciências Agrárias, Londrina, v. 28, n. 2, p. 241-250, abr./jun. 2007. 
FONSECA,Y. S. K.; DIAS, A. M. G.; RISSETO, M. R.; SOTO, F. R. M. Toxinfecção alimentar por Bacillus cereus: Relato de caso. Revista Higiene Alimentar, Mirandópolis, v. 19, n. 130, p. 33-36, 2005.

FURLANETO, L.; KATAOKA, A. F. A. Análise microbiológica de lanches comercializados em carrinhos de ambulantes. Lecta, Bragança Paulista, v. 22, n. 1-2, p. 49-52, jan./dez. 2004.

INSTITUTO ADOLF LUTZ - IAL. Métodos químicos e físicos para análise de alimentos. 4. ed. São Paulo: Ed. Adolf Lutz, 2008. 595 p.

$\begin{array}{lrr}\text { INTERNATIONAL } & \text { COMISSION } & \text { ON } \\ \text { MICROBIOLOGICAL } & \text { SPECIFICATIONS } & \text { FOR }\end{array}$
FOODS - ICMSF. Microrganismos de los alimentos. 2. ed. Zaragoza: Editorial Acribia, 1983. 341 p. (Técnica de analyses microbiológico, v. 1).

LOPES, F. N. O.; MADOKORO, R. Y.; MARTINS, V. F. Análise da conservação de alimentos à venda em lanchonetes da UNICAMP. Revista Ciências do Ambiente On-Line, Campinas, v. 6, n. 1, p. 34-38, jun. 2010.
PEIXOTO, D.; WECKWERH, P. H.; SIMIONATO, E. M. R. S. Avaliação da qualidade microbiológica de produtos de confeitaria comercializados na cidade de Ribeirão Preto/SP. Alimentos e Nutrição, Araraquara, v. 20, n. 4, p. 611-615, out./dez. 2009.

PIMENTEL GOMES, F. Curso de estatística experimental. 11. ed. Piracicaba: Livraria Nobel, 1985. $466 \mathrm{p}$.

SILVA, N.; JUNQUEIRA,V. C. A.; SILVEIRA, N. F. A. Manual de métodos de análise microbiológica de alimentos. 2. ed. São Paulo: Livraria Varela, 2001. 317 p.

SOTO, F. R. M.; RISSETO, M. R.; LÚCIO, D.; SHIMOZAKO, H. J.; CAMARGO, C. C.; IWATA, M. K.; CAMARGO, C. A.; OLIVEIRA, E.; CAMARGO, S. R. Metodologia de avaliação das condições sanitárias de vendedores ambulantes de alimentos no Município de Ibiúna-SP. Revista Brasileira de Epidemiologia, Cerqueira César, v. 11. n. 2, p. 297-303, 2008.

VANZOLINI, E. P. Métodos estatísticos elementares em sistemática zoológica. São Paulo: Ed. Hucitec, 1993. 130 p. 